\title{
Experimental models in the investigation of device-related infections
}

\author{
Werner Zimmerh \\ Division of Infectious Diseases, University Hospital, Petersgraben 4, \\ CH-4031 Basel, Switzerland
}

\begin{abstract}
There has been an increasing concern with the problem of device-related infections, ever since foreign materials such as metal or plastic began to be used in implant surgery. The prophylaxis and treatment of such infections is difficult to evaluate in clinical studies, because placebo-controlled prophylaxis trials are thought to be unethical, and no single centre has enough patients for comparative treatment studies. For this reason different experimental models have been developed to study aspects of device-related infections. In this review, these infection models are presented. Different applications of the tissue-cage guinea pig model are summarized. This model allows the study of pathogenesis, natural course, prophylaxis, and treatment of device-related infection. In addition, by using this infection model, novel microbiological in-vitro tests could be developed, and questions of biocompatibility analysed.
\end{abstract}

\section{Introduction}

During the last four decades, metals or plastics have been increasingly used for different types of devices (Ingraham, Alexander \& Matson, 1947; Pudenz et al., 1957; Charnley, 1972; Szilagyi et al., 1972). Of all problems associated with such implants, the most severe is infection. The commonest microorganisms involved in such infections are Staphylococcus aureus, Staphylococcus epidermidis and Escherichia coli. However, any microorganism may be implicated (Andrews et al., 1981; Widmer et al., 1990a). Without removal of the foreign material, antimicrobial therapy often fails to cure device-related infections (Dougherty, 1988).

During the last ten years, different experimental models have been used to elucidate the multiple problems encountered in device-related infections (Zimmerli et al., 1982; Zimmerli, Lew \& Waldvogel, 1984; Zimmerli, Zak \& Vosbeck, 1985; Widmer et al., $19906,1991)$. Whereas in the early eighties the main research effort was directed to the study of pathogenesis (Zimmerli et al., 1982, 1985), within the last five years much has been learned about drug therapy and prophylaxis of device-related infection (Bouchenaki et al., 1990; Widmer et al., 1990b, 1991).

\section{Animal modeks of device-related infections}

\section{Suture model}

James \& MacLeod (1961) developed the stitch abscess model in the mouse. In their experimental model of superficial skin infection, they could show that the presence of

97

0305-7453/93/31D097+06 508.00/0 1993 The British Society for Antimicrobial Chemotherapy 
suture material decreased the abscess-forming dose from $10^{7} \mathrm{cfu}$ to $10^{2} \mathrm{cfu}$ of $S$. aureus. Despite a heavy granulocyte infiltration surrounding the suture, the infection could not be eliminated. With these experiments, the high susceptibility to infection, and the persistence of established infection, could be experimentally demonstrated for the first time.

Following these experiments, the same experimental model was used to analyse the infection potentiating properties of different suture materials (Katz, Mordechai \& Mirelman, 1981).

\section{Vascular graft model}

After the introduction of vascular grafts in clinical medicine, the problem of vascular graft infection was studied in experimental models. Dogs are the experimental animals commonly used (Busuttil et al., 1979). Other experimental animals that have been used are pigs, minipigs, calves and baboons (Kron et al., 1980). The following aspects have been studied using the vascular graft model: healing characteristics (e.g. the influence of pseudointimal integrity on susceptibility to infection) the influence of material on development of infection, and the pathogenesis of haematogenous infections.

\section{Catheter and prosthetic valve endocarditis model}

Garrison \& Freedman (1970) developed the first model of endocarditis. They used a catheter to induce and maintain endocarditis in rabbits. With a similar model in rats, aspects of endocarditis prophylaxis have been extensively studied (Glauser et al., 1983). These models gave the rational background for the recommendations regarding antimicrobial prophylaxis for the prevention of bacterial endocarditis. In another, more sophisticated model, tricuspid prosthetic valve endocarditis was studied in calves (Grogan et al., 1980). This model can be used to study the technical problems of prosthetic-valve replacement, the quality of different prosthetic materials and the natural history of prosthetic-valve endocarditis, and to test the efficacy of antibiotic prophylaxis and treatment.

\section{Knee joint model}

Blomgren et al. (1981) implanted finger endoprostheses into rabbit knees in order to study haematogenous infections in the joint implant. The same model is useful for the systematic study of antibiotic prophylaxis.

\section{Tissue cage model}

The tissue-cage model has been developed to study various aspects of prosthetic infections, including the pathogenetic mechanisms leading to the high susceptibility of implanted devices to infection and their persistence (Zimmerli et al., 1982, 1984, 1985). In this model, perforated polymer cylinders are subcutaneously implanted into guinea pigs. 
Table. Application of the tissue-cage model

\begin{tabular}{|c|c|}
\hline Clinical problem & References \\
\hline Local immune deficiency & Zimmerli et al. $(1982,1984)$ \\
\hline $\begin{array}{l}\text { Risk of haematogenous seeding on } \\
\text { extravascular devices }\end{array}$ & Zimmerli et al. (1985) \\
\hline Efficacy of prophylaxis & $\begin{array}{l}\text { Tshefu et al. (1983), Zimmerli et al. (1984), } \\
\text { Widmer et al. (1991) }\end{array}$ \\
\hline Efficacy of therapy & $\begin{array}{l}\text { Tshefu et al. (1983), Zimmerli et al. (1985), } \\
\text { Widmer et al. (1990a,b, 1991), Bouchenaki } \\
\text { et al. (1990) }\end{array}$ \\
\hline $\begin{array}{l}\text { Correlation between drug efficacy in vivo and } \\
\text { in device-related infections }\end{array}$ & $\begin{array}{l}\text { Widmer et al. (1990a, 1991), Vergères et al. } \\
\text { (1992) }\end{array}$ \\
\hline $\begin{array}{l}\text { Testing of biomaterials } \\
\text { (biocompatibility, susceptibility to } \\
\text { infection) }\end{array}$ & Widmer et al. (1992) \\
\hline
\end{tabular}

\section{Application of the tissue-cage model}

The Table shows different aspects that have been studied with the tissue-cage model.

\section{Study of the pathogenesis of device-related infections}

Tissue cages are subcutaneously implanted into guinea pigs. This imitates the clinical situation of extravascular devices such as pacemaker batteries, subcutaneous catheters and shunts, breast implants, etc. The accumulation of interstitial fluid and leucocytes in the vicinity of the tissue cage allows study of local host defence mechanisms. We observed a locally acquired granulocyte defect which may be responsible for the high susceptibility of implants to infection (Zimmerli et al., 1982, 1984). There is evidence that this defect is a consequence of the prolonged stimulation of the granulocyte by the non-phagocytosable implant.

\section{Haematogenous implant infection}

Whereas infection up to one year after surgery is mostly due to intra-operative contamination, little is known about the pathogenesis of late prosthetic infections. We employed the tissue-cage model to determine whether extravascular devices could be infected by the haematogenous route (Zimmerli et al., 1985). Intracardiac inoculation of 50 million cfu $S$. aureus Wood 46, resulting in bacteraemias of $10^{2}-10^{3} \mathrm{cfu} / \mathrm{mL}$, led to selective infection in $42 \%$ of the tissue cages without microbiological evidence of infection elsewhere. These experiments indicate that antibiotic prophylaxis might be considered in patients with extravascular devices undergoing procedures complicated by bacteraemia.

\section{Efficacy of prophylaxis}

The tissue-cage model described can be used to analyse the conditions for adequate antimicrobial prophylaxis. By testing different time intervals between bacterial inoculation and start of treatment, the importance of timely prophylaxis and the need for multiple doses could be evaluated (Tshefu et al., 1983; Zimmerli et al., 1985). In tissue 
cages which were directly inoculated with $S$. aureus Wood 46, prophylaxis with four doses of rifampicin was $100 \%$ efficient before and up to $3 \mathrm{~h}$ after, but only $57 \%$ efficient $24 \mathrm{~h}$ after bacterial challenge (Tshefu et al., 1983). With doses of rifampicin starting either before, or up to $3 \mathrm{~h}$ after, experimental bacteraemia with $S$. aureus, no implant infection occurred (Zimmerli et al., 1985). Similar results were obtained with $E$. coli as the test strain (Widmer et al., 1991).

\section{Efficacy of therapy}

Device-related infections tend to persist despite treatment with an antibiotic with excellent in-vitro activity (Dougherty, 1988; Widmer et al., 1990a). We therefore analysed the efficacy of different antimicrobial drugs against $S$. epidermidis (Widmer et al., 1990b), S. cureus (Zimmerli et al., 1991), E. coli Widmer et al., 1991), and Salmonella dublin (Widmer et al., 1990a). The main finding in these studies was that rifampicin-containing regimens were much more efficient against staphylococci than any other drug (Widmer et al., 1990b; Zimmerli et al., 1991). However, rapid emergence of resistance was observed if rifampicin was given alone (Zimmerli et al., 1991). In Gram-negative infections, quinolones were the most efficient drugs (Widmer et al., 1990a, 1991).

\section{Development of in-vitro tests to predict drug efficacy in device-related infection}

The choice of a therapeutic antimicrobial agent is usually guided by the in-vitro susceptibility (MIC) of the microorganism to the drug. In treating device-related infections, this choice is obviously often not adequate, since the infection persists, regardless of the length of the treatment (Widmer et al., 1990a). We therefore looked for more appropriate in-vitro tests which take into account the special situation of device-related infections. In these infections bacteria are likely to be in the stationary phase of growth, against which all antibiotics show a diminished activity. Furthermore, bacterial adherence to foreign materials alters their susceptibility to antimicrobial agents.

We used the tissue-cage model to validate novel microbiological tests taking into account the above mentioned properties of the microorganisms. These studies showed that drug efficacy on stationary and adherent microorganisms, but not MICs, predicted the outcome of device-related infection (Widmer et al., 1990a, 1991; Vergères et al., 1992).

\section{Tests of biocompatibility}

Most biocompatibility tests are performed with cell culture systems and/or histology specimens from animals with bioimplants. However, these tests do not allow evaluation of the correlation between biocompatibility and infection susceptibility of foreign materials.

We used the tissue-cage model to study this correlation. By implanting two different materials (Teflon and ceramic), we tested the minimal infecting dose on the one hand, and the degree of inflammation (leucocyte counts and protein levels in tissue-cage fluid) on the other hand. In a first study we could show a direct correlation between biocompatibility and resistance to infection. Ceramic tissue cages provoked more 
inflammation, but were ten times more susceptible to infection with $S$. epidermidis than Teflon cages (Widmet et al., 1992).

\section{Conclusions}

The use of animal models has allowed us an insight into pathogenesis, prophylaxis, and treatment of device-related infections. As soon as a reproducible in-vitro test allows prediction of the efficacy of antimicrobial drugs in such infections, animal experiments will be redundant. However, the tissue-cage model will still be useful to test the relation between biocompatibility and infection susceptibility of different clinically important biomaterials.

\section{References}

Andrews, H. J., Arden, G. P., Hart, G. M. \& Owen, J. W. (1981). Deep infection after total hip replacement. Journal of Bone and Joint Surgery 63-B, 53-7.

Blomgren, G., Lundquist, H., Nord, C. E. \& Lindgren, U. (1981). Late anaerobic haematogenous infection of experimental total joint replacement. A study in the rabbit using Propionibacterium acnes. Journal of Bone and Joint Surgery 63-B, 614-8.

Bouchenaki, N., Vaudaux, P. E., Huggler, E., Waldvogel, F. A. \& Lew, P. D. (1990). Successful single-dose prophylaxis of Staphylococcus aureus foreign body infections in guinea pig by fleroxacin. Antimicrobial Agents and Chemotherapy 34, 21-4.

Busuttil, R. W., Rees, W., Baker, D. \& Wilson, S. E. (1979). Pathogenesis of aortoduodenal fistula: experimental and clinical correlates. Surgery 85, 1-13.

Charnley, J. (1972). Postoperative infection after total hip replacement with special reference to air contamination in the operating room. Clinical Orthopaedics and Related Research 87, $167-87$.

Dougherty, S. H. (1988). Pathobiology of infection in prosthetic devices. Review of Infectious Diseases 10, 1102-17.

Garrison, P. K. \& Freedman, L. R. (1970). Experimental endocarditis. I. Staphylococcal endocarditis in rabbits resulting from placement of polyethylene catheter in the right side of the heart. Yale Journal of Biology and Medicine 42, 394-410.

Glauser, M. P., Bernard, J. P., Moreillon, P. \& Francioli, P. (1983). Successful single-dose amoxicillin prophylaxis against experimental streptococcal endocarditis; evidence of two mechanisms of protection. Journal of Infectious Diseases 146, 568-75.

Grogan, E. L., Sande, M. A., Clark, R. E. \& Nolan, S. P. (1980). Experimental endocarditis in calf after tricuspid valve replacement. Annals of Thoracic Surgery 30, 64-9.

Ingraham, F. D., Alexander, E. \& Matson, D. D. (1947). Synthetic plastic materials in surgery. New England Journal of Medicine 236, 362-8.

James, R. C. \& MacLeod, C. J. (1961). Induction of staphylococcal infections in mice with small inocula introduced on sutures. British Journal of Experimental Pathology 42, 266-77.

Katz, S., Mordechai, I. \& Mirelman, D. (1981). Bacterial adherence to surgical sutures. Annals of Surgery 194, 35-41.

Kron, I. L., Georgitis, J. W., Holmes, P. \& Britton, R. C. (1980). Propagation of sepsis in vascular grafts. Archives of Surgery 115, 878-9.

Pudenz, R. H., Russell, F. E., Hurd, A. H. \& Shelden, C. H. (1957). Ventriculo-auriculostomy. A technique for shunting cerebrospinal fluid into the right auricle. Journal of Neurosurgery 14, $171-9$.

Szilagyi, D. E., Smith, R. F., Elliott, J. P. \& Vrandecic, M. P. (1972). Infection in arterial reconstruction with synthetic grafts. Annals of Surgery 176, 321-33.

Tshefu, K., Zimmerli, W. \& Waldvogel, F. A. (1983). Short-term rifampin administration of rifampin in the prevention or eradication of foreign body infection due to foreign bodies. Reviews of Infectious Diseases 5, Suppl. 3, S474-80.

Vergères, P., Zimmerli, W., Widmer, A. F. \& Blaser, J. (1992). In-vivo verification of an in-vitro model of antibiotic treatment of device-related infection (DRI). In Program and Abstracts of 
the Thirty-Second Interscience Conference on Antimicrobial Agents and Chemotherapy, Anaheim, CA, 1992. Abstract 514. American Society for Microbiology, Washington, DC.

Widmer, A. F., Colombo, V. E., Gāchter, A., Thiel, G. \& Zimmerli, W. (1990a). Salmonella infection in total hip replacement: tests to predict the outcome of antimicrobial therapy. Scandinavian Journal of Infectious Diseases 22, 611-8.

Widmer, A. F., Frei, R., Rajacic, Z. \& Zimmerli, W. (1990b). Correlation between in vivo and in vitro efficacy of antimicrobial agents against foreign-body infections. Journal of Infectious Diseases 162, 96-102.

Widmer, A. F., Ochsner, P. E. \& Zimmerli, W. (1992). Biocompatibility and resistance to infections of Teflon and ceramic (TCP) implants in guines pigs. In Program and Abstracts of the Ninety-Second Annual Meeting of the American Society for Micrabiology, New Orleans, 1992. Abstract B-238, p. 65. American Society for Microbiology, Washington, DC.

Widmer, A. F., Wiestner, A. Frei, R. \& Zimmerli, W. (1991). Killing of nongrowing and adherent Escherichia coli determines drug efficacy in device-related infections. Antimicrobial Agents and Chemotherapy 35, 741-6.

Zimmerli, W., Frei, R. \& Rajacic, Z. (1991). The role of fleroxacin (F), ciprofloxacin (C) and rifampin (R) in experimental device-related infections with 3 clinical isolates of Staphylococcus aureus (SA). In Program and Abstracts of the Thirty-First Interscience Conference on Antimicrobial Agents and Chemotherapy, Chicago, IL, 1991. Abstract 1198. American Society for Microbiology, Washington, DC.

Zimmerli, W., Lew, P. D. \& Waldvogel, F. A. (1984). Pathogenesis of foreign body infection. Evidence for a local granulocyte defect. Journal of Clincal Investigation 73, 1191-200.

Zimmerli, W., Waldvogel, F. A., Vaudaux, P. \& Nydegger, U. E. (1982). Pathogenesis of foreign body infection: description and characteristics of an animal model. Journal of Infectious Diseases 146, 487-97.

Zimmerli, W., Zak, O. \& Vosbeck, K. (1985). Experimental haematogenous infection of subcutaneously implanted foreign bodies. Scandinavian Journal of Infectious Diseases 17, 303-10. 